\title{
Article \\ Disclosure of Intellectual Capital Components in Integrated Reporting: An Empirical Analysis
}

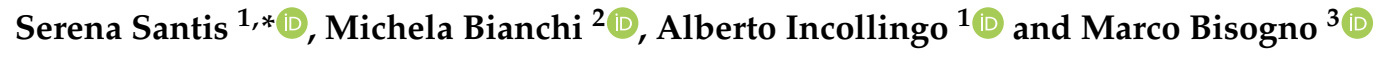 \\ 1 Department of Political Science “Jean Monnet", University of Campania “Luigi Vanvitelli", Viale Ellittico, \\ no. 31, 81100 Caserta, Italy; alberto.incollingo@unicampania.it \\ 2 Department of Political Science, University of Roma Tre, Via Gabriello Chiabrera, 199, 00145 Rome, Italy; \\ michela.bianchi@uniroma3.it \\ 3 Department of Management \& Innovation Systems, University of Salerno, Giovanni Paolo II, no. 132, \\ 84084 Fisciano (SA), Italy; mbisogno@unisa.it \\ * Correspondence: serena.santis@unicampania.it; Tel.: +39-0823-275227
}

Received: 30 November 2018; Accepted: 20 December 2018; Published: 22 December 2018

check for updates

\begin{abstract}
The purpose of the study is to investigate how firms disclose information in their integrated report (IR) on intellectual capital (IC), regarding its components and their link with the value creation process. Therefore, by adopting a content analysis methodology, the study, which covers three years (2014-2016), is focused on IC. A sample of firms belonging to the financial services sector is investigated by analysing 135 integrated reports. The main findings show that firms, on the one hand, provide information on IC by adopting a classification close to those outlined by IC scholars; on the other hand, the vast majority of the investigated firms tends to adopt a superficial approach. More specifically, firms disclose a low amount of information about the link between IC and the value creation process, even though they are aware of its importance.
\end{abstract}

Keywords: integrated reporting; intellectual capital; disclosure

\section{Introduction}

In recent years, the role of external reporting has developed, showing the relevance of non-financial information that has to be included in integrated reporting (IR) [1-5]. In fact, non-financial information, together with financial information, clarifies the whole status of the firm, satisfying the required level of transparency and accountability for stakeholders [6-8] and better supporting the decision-making process [9]. The International Integrated Reporting Council (IIRC) highlights that IR is "a concise communication about how an organization's strategy, governance, performance and prospects, in the context of its external environment, lead to the creation of value over the short, medium and long-term" [6] (Part 1.1). More specifically, to create and sustain value, the IIRC Framework refers to six capitals: namely financial, manufactured, intellectual, human, social and relationship, and natural capital. The IIRC Framework considers these capitals as fundamental concepts of IR that are strictly and directly linked to the value creation process, although they may not be considered equally relevant.

Several papers have investigated how organisations measure their intellectual capital (IC), analysing potential key determinants of IC value [10], and how they report its components [11]. However, few studies $[12,13]$ have concentrated on the importance of IC within the IR, investigating its contribution to value creation [14]. The relevance of this component could be explained in the light of the growing importance of intangible assets [15], whose market value has been increased since the 1970s. However, it should be noted that the meaning of IC within the IR, the identification of its components and the function they have in the value creation process seem not to be particularly 
evident, with a risk of overlapping and possible misunderstandings. Accordingly, and following the third IC research stage [16], it would be interesting to understand how IC is classified and implemented by firms while preparing their IR.

Therefore, this paper intends to do this, in order to assess whether the IC concept adopted by firms complies with the IIRC Framework requirements and definitions or if firms adopt a more comprehensive approach, in line with the IC literature classification. In this way, this study aims to give evidence of emerging practices in the field of IR, responding to the call for how this reporting is implemented and the challenges associated with practising it [17].

Using a content analysis performed with a disclosure index, the study investigates 135 integrated reports (IRs) in three years $(2014,2015$ and 2016) of 45 companies belonging to the financial services sector. The main findings emerging from the study are that the investigated firms tend to go beyond the classification proposed by the IIRC Framework, adopting a classification close to those outlined by IC researchers. Furthermore, about $70 \%$ of firms tends to provide a low volume of information regarding the IC components and their role towards the value creation process.

The remainder of the article is structured as follows. Section 2 introduces the background, providing a review of the relevant literature about the integrated reporting and the intellectual capital. Section 3 illustrates the research methodology. Section 4 presents the results, which are discussed in Section 5 , along with the conclusion and further developments of the research.

\section{Literature Review}

In the last few years, an increasing number of scholars has been investigating the concept and the purpose of IR, which represents one of the most debated issues regarding external financial reporting, as it affects (and brings together) many topics which have so far been studied separately.

The first contributions have highlighted that the integrated report is an informative channel, which encourages firms to adopt more responsible behaviour [18-21]. Scholars point out its characteristics through a comparison between this report and the traditional sustainability reports [22] and its origins and developments for professional and academic training [23]. Other studies have developed a model based on the description of capital and governance [24], carrying out a practical analysis of both the content and form [7]. Following these studies, scholars have pointed out two main critical aspects.

Firstly, they have underlined the need to investigate the content of the reports, to understand if the aims of this new reporting approach are realistic and achievable in practice. Accordingly, many studies have replied to such a call. Several papers have examined emerging integrated reporting practices [8,25-33]; some of them have focused on the application of the IIRC Framework's guiding principles [34-37] and users' benefits [26,38].

Secondly, several papers have dealt with the theoretical problems and the concrete challenges due to the different ways of applying and interpreting such a report $[4,17,39,40]$. Flower [41] criticises the IIRC approach, claiming that, in the final version of the Framework, the sustainability accounting was, in fact, abandoned; furthermore, he underscores the limited prescriptive power of the Framework, with one the main consequences being that it cannot influence the future practices of corporate reporting.

Recently, some literature reviews on integrated reporting have been published, giving an insight into how IR research is developing, providing a critical analysis and outlining a future research agenda [42-46]. Accordingly, this paper desires to contribute to the debate concerning the interpretation and application of the IIRC Framework, analysing whether and how organisations disclose its "fundamental concepts" (capitals and value creation process). As stated previously, to create and sustain value, the IIRC Framework refers to six capitals (financial, manufactured, intellectual, human, social and relationship, and natural capital), emphasising the link with the value creation process, even though the six capitals may not be considered equally relevant.

Previous studies have investigated how organisations measure their intellectual capital (IC) [10] and report its components [11], even though IC reports are not very common in practice [47]. 
Other research $[13,48]$ has concentrated on the importance of (IC) within the IR, investigating its contribution to the value creation process [14]. Since IR largely refers to IC, these studies call for further research to investigate IC management and reporting within the IIRC Framework, as "undoubtedly IC is undergoing a resurgence as part of IR" [15] (p. 11).

The IIRC Framework [6] (Section 2.15) defines intellectual capital as organisational, knowledge-based intangibles including (i) "intellectual property, such as patents, copyrights, software, rights and licences"; and (ii) "organizational capital such as tacit knowledge, systems, procedures and protocols". It is worth noting that the IIRC Framework considers human capital and social and relational capital as separate capitals, while IC studies adopt a different approach. In fact, although there is no a generally accepted definition of IC in the literature $[15,48-50]$, scholars refer to a tripartite classification: human capital, relational (or external) capital, and structural (or internal or organisational) capital [51-55].

Human capital refers to people's capabilities and the intangible value they are endowed with, namely knowledge and skills which strengthen the organisations' capacity to make decisions and allocate resources $[16,56]$.

Relational capital refers to the intangible resources capable of generating value connected with external relationships, such as those with customers, suppliers and research and development partners.

Structural capital refers to the resources within the entity, comprising databases, organisational routines, procedures, mechanisms and structures of the organisation that support employees in their quest for optimum intellectual performance $[53,57]$.

This classification does not comply with that provided by the IIRC Framework; however, whatever approach is preferred, IC is supposed to sustain the firm's strategies and the value-creation process. Previous studies [58] claim that the definition of IC provided by the IIRC Framework substantially adheres to the definition of structural capital. Along this line of thought, Badia et al. [59] argue that the definition of IC largely accepted by the literature (and based on the tripartite classification previously mentioned) tends to comprise at least three out of the six types of capital (intellectual, human, and social and relationship) mentioned in the IIRC Framework. However, further studies are called for to investigate IC management and reporting within the IIRC Framework [42]. Therefore, the first research question this study will focus on is as follows:

Question 1. How do firms disclose information on intellectual capital, and which are the components they identify?

Other studies [60] suggest considering human capital in a wider perspective, which includes staff and external stakeholders' competencies, to be investigated (also) in their connection with sustainability. Furthermore, scholars call for the adoption of a critical approach while investigating IC, suggesting a need to embrace a broader research strategy to the value creation issues, in order to include social and environmental values [61]. In fact, integrated reports should be structured so as to allow the reader to understand the connections between the IC components, as illustrated in the IIRC Framework, and the context in which businesses operate, in order to thoroughly explain the company's value creation process $[27,35]$. However, considering that the link between value creation and both IC and IR seems to be taken for granted ("unproven" [42]), there is a need to adopt a critical approach while examining IR, avoiding the presumption of its advantages.

Therefore, there should be a focus on how firms implement IR, following the suggestion of Dumay et al. [42], who question the need for further normative research, underlying that it is now time to test the IIRC's rhetoric. Accordingly, this study aims to understand how companies interpret IC while preparing their IR, what the meaning they assign to this concept is and how it is represented in the IR, in light of the value creation process. Therefore, the second research question of this study is as follows:

Question 2. Do firms provide information concerning the link between intellectual capital and the value creation process? 


\section{Research Methodology}

This study analyses the integrated reports of a large sample of firms belonging to the financial services sector, which have published their IR over three years (2014, 2015 and 2016). Among the different sectors included in the IIRC database, this study focuses on this specific context to overlap the difficulties and the different forms, functions and role of the IC in the different sectors [62]; additionally, the financial services sector was selected because of the relevance of both human and technological skills, and because it is the largest one. Fifty-one firms are contained in the database (http:/ / examples.integratedreporting.org/all_organisations; research on May 30, 2018).

Therefore, the integrated report of each firm for the three years was downloaded. Four firms did not provide IR for all the selected years, so they were excluded from the sample. Moreover, a firm was inadvertently included twice in the database (by using a long name and an acronym), while another firm changed its name during the investigated period. Therefore, the final sample consisted of 45 companies (see Appendix A), with the total number of integrated reports investigated being 135.

As far as the methodological perspective is concerned, this research is based on the disclosure index technique, which is a partial and semi-objective form of content analysis of narratives in annual reports. Adopting this approach implies the need to provide an ex ante definition of a list of items to be found in the text [63], allowing readers to interpret the results and researchers to replicate the analysis [55]. This technique is consistent with the research objectives of the study, as it allows a rich description of the company's narrative disclosures, identifying characteristics embedded in the reports and quantifying qualitative information.

In particular, the disclosure index is a research instrument that aims to show the level of disclosure in a set of company accounts [64], while content analysis consists of a research technique for the objective, systematic, and quantitative description of the manifest content of communication [65-67].

The research methodology consists of different steps.

In the first step, each IR was analysed to discover if the different capitals (financial, manufactured, intellectual, human, social and relationship, natural) proposed by the IIRC Framework were illustrated and classified. A first disclosure index was developed as follows:

$$
D I=\frac{\sum_{i=1}^{n} d_{i}}{n}
$$

where

$d=1$ if the IIRC capital classification is found (more precisely, if the integrated report describes at least one of IIRC capitals other than the financial one), and 0 otherwise;

$n=135$ (total number of integrated reports analysed).

Retaining as a reference the definition provided by the IIRC Framework, the analysis subsequently focuses on IC to understand how it is interpreted and disclosed in practice [68]. Accordingly, the second step is based on the following phases [69]:

- A selection of items that can be considered as IC components;

- An identification of the categories of items;

- An elaboration of a disclosure scoring sheet;

- The development of a scoring scheme to capture the level of disclosure;

- An analysis of the specific integrated report sections for scoring the items;

- A construction of the disclosure indices.

The items related to IC, as illustrated in the investigated IRs, were searched for by bearing in mind the specific requirements of the IIRC Framework. As clarified in the previous section, the focus on IC was due to its importance within the IR and its contribution to the value creation, as this was underlined by several studies $[12,13]$. 
Therefore, we grouped individual items into the two IC components, as defined by the IIRC Framework [6] (Section 2.15), namely:

- Intellectual property;

- Organizational capital.

However, considering the flexibility allowed by the IIRC Framework, another (residual) component of IC was added, which includes all other types of IC disclosed by firms, which are not covered by the IIRC classification.

The third step regarded the preparation of a list of disclosure items: in particular, a disclosure scoring sheet, made up of 14 items (selected in the first phase) grouped into 3 categories (identified in the second phase), was elaborated. The scoring sheet is shown in Appendix B.

The fourth step referred to the development of a scoring scheme to capture the level of disclosure carried out by using a dichotomous procedure, in which each category scores 1 if at least one item was disclosed, and 0 otherwise [69]. Therefore, the intellectual capital disclosure (ICD) score for each category is additive:

$$
I C D=\sum_{i=1}^{m} d_{i}
$$

where

$d=1$ if an item $d_{\mathrm{i}}$ is disclosed, and 0 otherwise;

$m=$ total number of IC disclosed.

The fifth step dealt with the analysis of the integrated reports for scoring the items. To ensure the reliability of the analysis, an inter-coder reliability, which is one of the three common forms of reliability (test-retest, inter-coder reliability, and internal consistency [70]) was used. This form of reliability refers to the extent to which a content classification produces the same results when the same text is coded by more than one coder [67]. In particular, the collection of the data was carried out by two coders, using a self-constructed standard coding that was developed in compliance with the IIRC Framework (accuracy) [66]. Moreover, any discrepancy between the coders has been analysed, and any differences have been resolved.

Finally, a disclosure index was developed. This index is a ratio of the scores assigned to each category to the number of IC disclosed. Therefore, for each IC component, the IC index was defined as:

$$
I C=\frac{I C D}{m}
$$

The IC index can assume values between the range of 0 and $100 \%$ : values near 0 denote a scarce presence of the IC component, while values near 100\% denote a strong presence.

In the last step, a more in-depth study was carried out, focusing on firms which have dedicated a specific section to illustrating IC.

\section{Results}

First of all, the research shows that 84 IRs describe at least two out of the six capitals as defined by the IIRC Framework; that is, $62 \%$ of the sample. This means that the remaining $38 \%$ of the 135 IRs focuses on a single capital (more specifically, financial capital) and seems not to follow the Framework guidelines.

Proceeding with the analysis for three years, the percentage of IR illustrating at least two capitals rises from $49 \%$ in 2014 to $62 \%$ in 2015, and to $76 \%$ in 2016, emphasising a growing awareness of how important it could be to provide information about more than a single capital.

It is also worth observing that the investigated firms provide this information in different sections, such as "Process of value creation", "Business model", or in more general sections such as "About this report" or "Measuring our strategic progress". 
Focusing on the 84 IRs which provide information on at least two out of the six capitals, Figure 1 shows the percentage of IRs which give information regarding the six capitals, as illustrated in the IIRC Framework [6]. While all the investigated IRs illustrate the financial capital, only $51 \%$ and $65 \%$ provide information regarding manufactured capital and natural capital, respectively. However, it is worth noting that a high percentage of IRs illustrates intellectual capital ( $82 \%$, which corresponds to 69 IRs out of 84), supporting the idea that IC (as defined by management literature) is experiencing a resurgence as a component of IR [15].

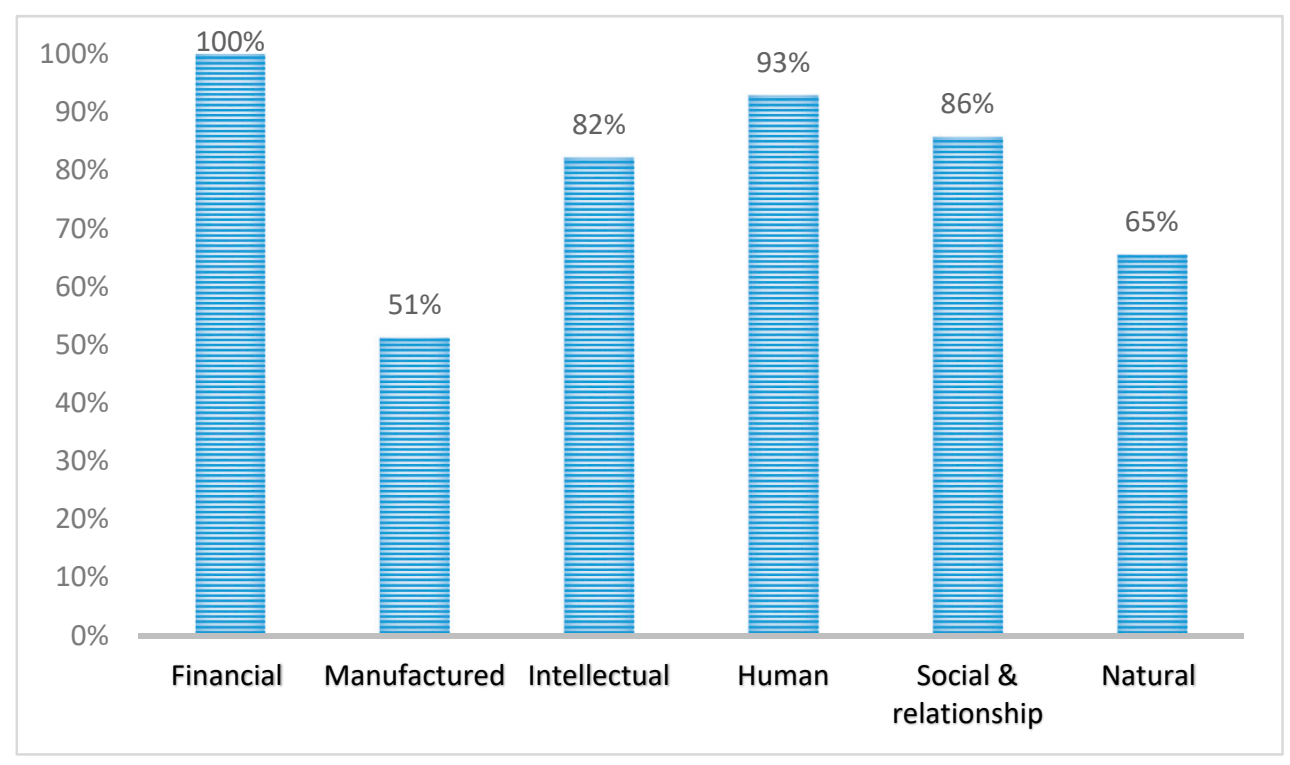

Figure 1. Percentages of integrated reports (IRs) showing the different capitals.

Focusing on IC, an ever-growing percentage of IRs disclosing information on its components is observed, ranging from $73 \%$ of the cases in 2014 to $82 \%$ in 2015 , and $88 \%$ in 2016.

Furthermore, it has been analysed how firms define and describe IC, illustrating its components. According to the research steps illustrated in the previous section, the first step of the analysis was based on the classification of IC provided by the IIRC Framework, referring to:

- Intellectual property: patents, copyrights, software, rights and licences;

- Organizational capital: tacit knowledge, systems, procedures and protocols, as well as databases, organisational routines, mechanisms and structures embedded in the organisation (implicitly considering also the definition of structural capital as suggested by the management literature).

Secondly, bearing in mind the flexibility allowed by the IIRC Framework, a residual category ("other") was included to collect all the other types of IC disclosed by firms, even though they are not covered by the IIRC Framework.

As Table 1 illustrates, among IRs which describe IC (69 for the whole three-year period), intellectual property is found in $25 \%$ of the cases, while organizational capital in $51 \%$. It is worth noting that the residual category ("other") is the most significant, as $81 \%$ of the cases includes information on IC not dealt with by the previous two categories.

Table 1. Intellectual capital components.

\begin{tabular}{cc}
\hline IC Components & $\%$ \\
\hline Intellectual property & $25 \%$ \\
Organizational capital & $51 \%$ \\
Other & $81 \%$ \\
\hline
\end{tabular}


As a result, the analysis examined this additional information in more depth.

In this respect, it is worth bearing in mind that the concept of IC tends to comprise at least three out of the six capitals (intellectual, human, and social and relationship) mentioned by the IIRC Framework $[47,58,59]$. However, to avoid using a predefined and rigid scheme, a wider approach was implemented, with the aim of also capturing other additional information provided by firms in their IR. More specifically, firstly, the classification mentioned above as suggested by scholars $[47,58,59]$ was used; secondly, having verified that this scheme risked losing data on IC that firms tend to provide in their IR, a wider plan of action was adopted. In so doing, the flexibility allowed by the IIRC Framework (Sections 2.16 to 2.18 ) was also taken into consideration.

The findings show that the most common idea of IC is based on "organisational/structural capital" (51\%). "Human capital", as a specific IC component, is disclosed in 39\% of the cases. Many IRs emphasise other two components, namely "brand" and "ICT" (39\% and 38\% respectively). Relational capital has been considered as a specific IC component in $29 \%$ of the cases, while intellectual property and ethic value are in $25 \%$ and $9 \%$ of the cases, respectively. Finally, further information, included in the residual category "other", has been provided in $19 \%$ of the cases. Figure 2 shows the IC components as disclosed by the investigated IRs.

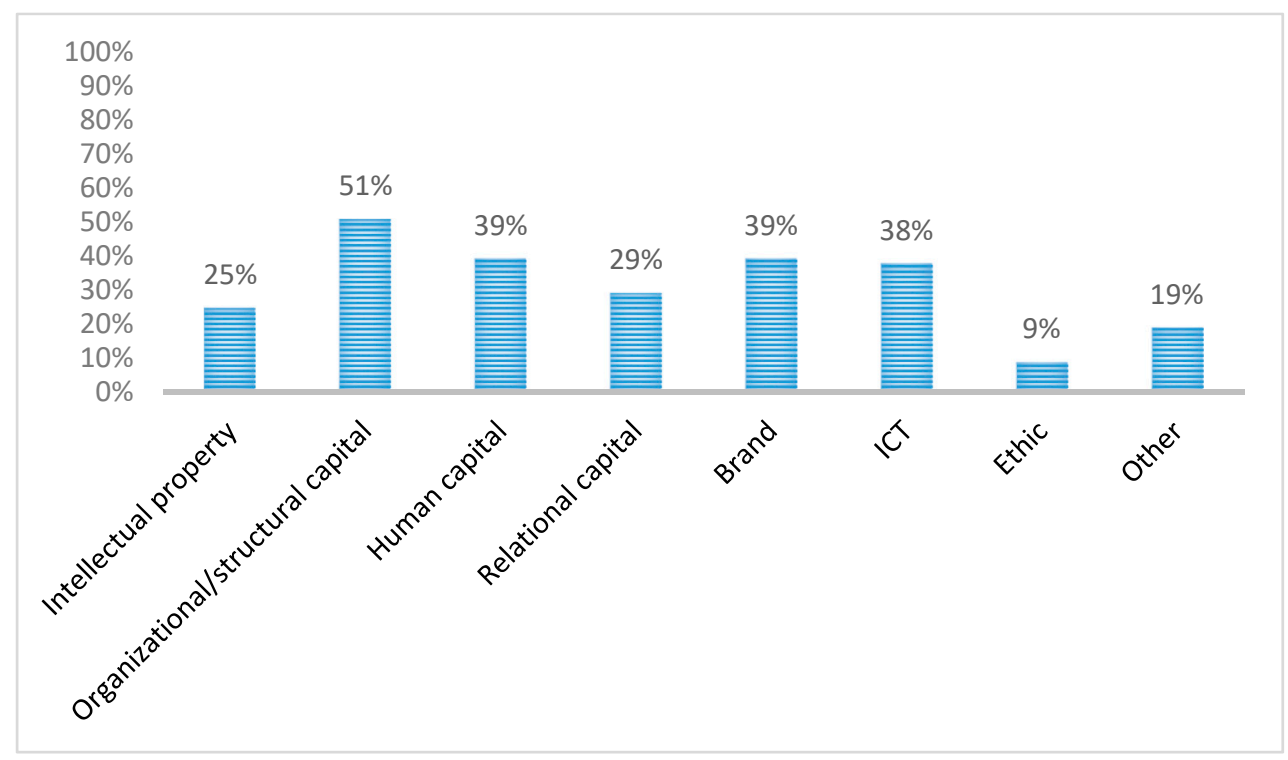

Figure 2. Intellectual capital components-detail.

As a result of the empirical analysis, the following classification of IC components was identified:

- Intellectual property: patents, copyrights, software, rights and licences;

- Organizational capital: tacit knowledge, systems, procedures and protocols, as well as databases, organisational routines, mechanisms and structures embedded in the organisation;

- Human capital: knowledge, skills and abilities of people which strengthen the organisations' capacity to make decisions and allocate resources;

- Relational capital: intangible resources capable of generating value connected with external relationships, such as those with customers, suppliers and research and development partners;

- Brand value: brand value, brand equity, brand image, brand reputation;

- Information and communications technology (ICT): information technology capabilities, innovation of new technologies and ability to develop new technologies, products and services; Innovation and digital banking;

- Ethic value: ethic, business ethics; corporate culture; 
- Other: Enterprise risk management framework, lending, investing and procurement practices, launched easy investing, discretionary portfolio investment scheme, market share; goodwill.

Therefore, it is clear that, according to the investigated sample, the definition of IC provided by the IIRC Framework is perceived as being too narrow; firms provide information which should be included in capitals other than IC. For example, firms are expected to provide information concerning human capital in the related Framework's capital. However, they consider it to be more appropriate to link it with other (perceived) related issues regarding IC, indirectly indicating the importance attributed to them.

Furthermore, Figure 3 shows the IC components used in three different years. An increasing trend can be observed only for three components: namely organizational/structural capital, ethic capital and relational capital, even if this last capital shows the same percentage (30\%) in the last two years. In most of the cases, there is a fluctuating trend such as for "intellectual property", "human capital", "ICT", and "other". Instead, and quite surprisingly, the component "brand" presents a decreasing trend.

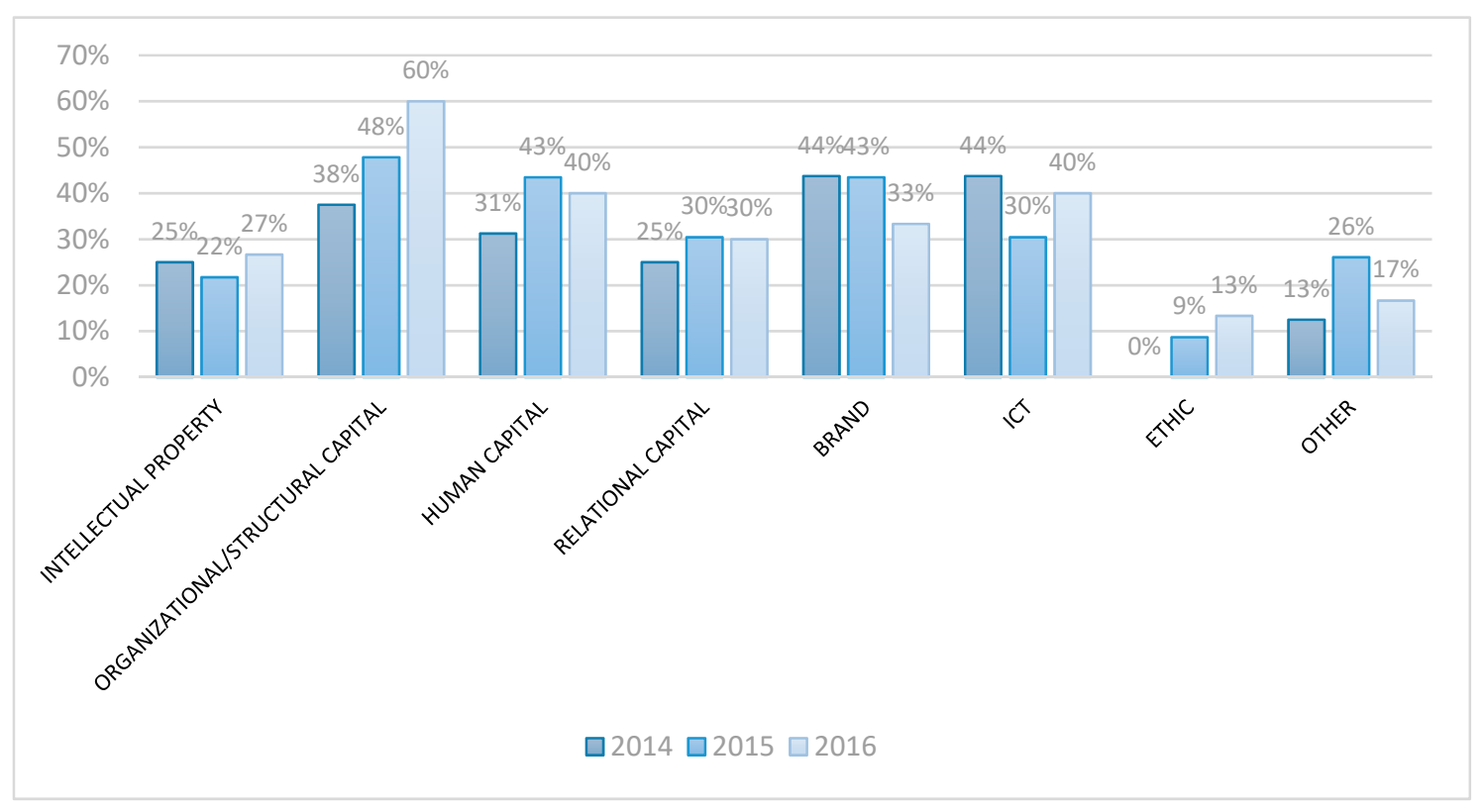

Figure 3. Intellectual capital components by year.

Having investigated what kind of information concerning IC firms disclose, we completed the analysis by considering how they disclose it. Indeed, while several IRs (70\%) provide little information, giving a mere description/definition of the IC components, only $30 \%$ dedicate a specific section to IC, highlighting its relevance for the value creation process, as Table 2 illustrates.

Table 2. Intellectual capital (IC) disclosure.

\begin{tabular}{cc}
\hline IC Disclosure & $\%$ \\
\hline Little information on IC & $70 \%$ \\
IC specific section & $30 \%$ \\
\hline
\end{tabular}

Accordingly, to investigate the second research question, the analysis was restricted to this second set of firms, investigating 21 IRs.

Several companies (Bank of Ceylon, 2016; LB Finance PLC, 2016, 2015; People's Leasing and Finance 2016) highlight how difficult it is to define and quantify IC. LB Finance $(2016,2015)$ states that, among the six capitals defined by IIRC Framework, IC is the most difficult one to measure, because of its intangible nature; however, the difficulties in calculating the value added do not mean that it can be disregarded. 
In each IR (except BNDES, 2016 and ItaùUnibanco, 2014), the specific section devoted to IC is focused on the analytic description of its components. It defines the achieved results (Bank of Ceylon, 2016, 2015; CCR SA, 2016, 2015, 2014); the actions taken by the company (BNDES, 2016) to improve IC ("The company also invests in training employees to improve their innovative talent", CCR SA, 2016 p. 32; IDLF Finance, 2016); and what the objectives and the status of the implementation are, compared to the established target (LB Finance PLC, 2016, 2015) or targets they would achieve in the following years (People's Leasing and Finance 2016; Fideuram, 2016; Bank of Ceylon, 2016). Along the same line, some sections describe the investments made on each element composed of IC (CCR SA, 2016, 2015; Unicredit, 2016, 2015, 2014).

Another aspect worth noting is that many companies consider brand value to be a fundamental part of the IC (Bank of Ceylon, 2016, 2015; Fnb Namibia Holdings, 2016; ItaùUnibanco, 2016, 2015, 2014; LB Finance PLC, 2016, 2015; People's Leasing and Finance 2016), although it belongs to the social and relational capital according to the IIRC Framework. The brand is tightly connected with value creation as a component of this process and, in particular, it is considered to be a key value-driver. Generally, the brand value is quantified with an estimated value, and in most of the cases, the IR dedicates a section on the evolution of the value brand over time.

A final critical aspect concerns the level of disclosure regarding the link between the IC and the value creation process. Several IRs include IC in their schematisation of the value creation process, consisting of a "pictorial portrayal" (Bank of Ceylon, 2016) or a "connections grid" (Fideuram, 2016) in which IC is a key component of their value creation process. UniCredit's IR (2014) highlights that some innovations positively affect the value for both the customers and the company. IC is likely to become an even more relevant asset and driver in the value creation process; however, this increase in value is not quantified but simply illustrated in a descriptive way. In general, most of the IRs do not explain how IC contributes to the generation of value for the company (Bank of Ceylon, 2016; BNDES, 2016; IDLC Finance, 2016; ItaùUnibanco, 2016; People's Leasing and Finance, 2016; Fideuram, 2016). Only a few try to provide a (weak) explanation of it ("CCR Group's value creation strategy also includes developing collaborations with universities and research centres to develop innovative solutions and technology that is adapted to the Group's requirements", CCR SA, 2016, p. 31).

Moreover, the analysis shows that only two IRs illustrate the connectivity between IC and the other capitals. In particular, LB Finance (2016) shows the connection in terms of value creation among the capitals and how the capitals impact on different stakeholders' groups: employees, business partners, society, customers, and so on. The Bank of Ceylon (2015, p. 94) explains how IC affects the other capitals, as required by the IIRC Framework:

- “Our human capital enriched with technical know-how, vast experience has been the driver in leading the transformational process to achieve this strategic priority.

- Intellectual capital has enabled us to strengthen our social and relationship capital instituting better systems and processes for faster, speedier delivery.

- The foundation for a paperless working environment has been constructed through the use of intellectual capital, permeating positives on the astute use of our natural capital.

- The tangible and intangible benefits emanating from the implementation of our intellectual capital is and will continue to impact our bottom line and hence our financial capital.

- Our manufactured capital is the structure upon which our intellectual capital has to be constructed, whether in brick and mortar structures or in investment in technology".

To recapitulate, the investigated firms tend to provide little information regarding how IC can contribute to the value creation, even though they seem to be aware of the importance and the function of the IC as a support to the value creation. In most of the cases, they report and manage each IC component, but they are concerned about their measurement. Several IRs expand the concept of value creation to incorporate other dimensions, such as the relevance of products and services to customers as shown by some companies (e.g., Unicredit, 2014) in their first IR. In other cases (TSKB, 
2016), a holistic approach is adopted, where different dimensions are unified in terms of financial analysis, technical expertise, and economic vision.

\section{Discussion and Conclusions}

This study has investigated the disclosure of IC components within the IR by analysing a large sample of firms belonging to the financial services sector. More specifically, it has examined how firms disclose information in their IR on IC, which are its components and their link with the value creation process. Through a content analysis methodology, a disclosure index has been calculated to answer the two research questions of the study.

The first one concerns the IC disclosure, whereas the second one refers to the level of information about the link between the IC and the value creation process within IRs.

As regards the first research question, the findings emerging from the analysis suggest the following considerations.

IRs that describe capital(s) other than the financial capital represent $62 \%$ of the sample, and this percentage rises from 2014 to 2016 . Consequently, 38\% of the 135 IRs focus on a single capital (financial capital) and seem not to follow the six capitals as identified by the Framework.

Among the reports describing at least two capitals, IC is mentioned or illustrated in $82 \%$ of the cases, demonstrating its importance for the firms.

Regarding the IC content, firms include items that, according to the IIRC Framework, should be included in other capitals. Firms tend to adopt a more comprehensive approach, in line with the IC literature classification [47]: apart from the "physical" capitals—namely financial, manufactured and natural capital—the other three "intangible" capitals broadly comply with the IC's three components. In fact, IRs disclose not only elements of the structural capital, but also items related to human and relational capital. These findings show that the IIRC definitions of IC are perceived as being too narrow. Besides this, the analysis of the trend of the IC content appears to be random.

Regarding the second research question, the findings show that the investigated firms tend to provide little information regarding how IC can contribute to the value creation process, although they seem to be aware of its importance and function as a support to the value creation. The vast majority of the investigated IRs do not explain how IC contributes to the value generation for the organisation, whereas only a few try to provide this information, with weak results. Moreover, only $30 \%$ of IRs that mention IC dedicate a specific section to it, but the particular attention received by IC does not necessarily lead to information of better quality.

Connectivity between the IC and other capitals is described only in 2 cases, and simply in terms of the increase of the capitals; in no case, a description of a decrease of the capitals or about trade-offs between the capitals was found.

To conclude, the vast majority of the investigated firms provide only a little information on IC, frequently "copying and pasting" the content of the IIRC Framework into their IR, adopting a superficial approach. Although firms are aware of the importance of IC, as a support to the value creation process, they disclose little information.

Therefore, these results firstly confirm what scholars have recently observed regarding some of the Framework's limitations, which make its implementation difficult. More precisely, the principle-based approach taken by the Framework, the flexibility and the lack of prescription concerning disclosure and metrics, the vague definitions about value creation, and the non-prescriptive categorisation of the six capitals lead to different ways in which IR is understood and enacted [61]. As a consequence, IRs are not comparable, since users are not able to identify similarities and differences among items, both in different periods and across different reporting entities.

Secondly, the inadequate disclosure regarding IC in the light of the value creation process and the interdependencies between capitals are also due to the subjective behaviour of the IR preparers. On the one hand, it is undeniable that (i) it is not easy to identify interdependencies and trade-offs between capitals; and (ii) firms are not motivated to describe decreases of capitals caused by the organisation's 
activities. On the other hand, it is argued that the poor quality and quantity of this kind of information represents a relevant deficiency of IRs, which ultimately implies the impossibility of reaching the true goal of the IIRC, that is, the full representation of the value creation process over time. At this stage of the journey towards integrated reporting, the lack of representation and measurements of (some categories of) capitals other than financial capital can be accepted, but the operators' response to the need for a holistic vision of the organisation for all the stakeholders must be considered inadequate. Therefore, the empirical analysis provides a classification of the IC disclosures that could be taken into consideration while investigating the contents of IRs and the connectivity between the different capitals [35].

However, IIRC should refine the Framework to avoid its "genetic ambiguity" regarding its purpose and users: if the "primary purpose of an integrated report is to explain to providers of financial capital how an organization creates value over time" [6] (Part 1.7), it is very difficult, as this research demonstrates, that "an integrated report benefits all stakeholders interested in an organization's ability to create value over time, including employees, customers, suppliers, business partners, local communities, legislators, regulators and policy-makers" [6] (Part 1.8). In other words, the critical point to solve is the meaning attributed to the word "value" [15] and, in this way, the real category of IR users.

One of the main implications emerging from this study is the evidence about the excessive vagueness of the definitions of the Framework, which is compromising the IIRC's intent to strike an appropriate balance between flexibility and prescription [6] (p. 4). The flexibility of the Framework can be considered necessary, as definitions require professional judgement to allow firms to adapt the report to their specific needs. However, the observed broad differences within the IRs of firms belonging to a specific sector clearly emphasise that this vagueness de facto represents a strong barrier to implement the IR following the Framework. Furthermore, this flexibility can allow firms to adopt a window-dressing approach, with the consequence being that IR does not affect the managerial behaviour.

The same vagueness concerns the concept of "value creation", whose measurement and representation are one of the critical objectives of the IR. The investigated IRs do not provide adequate information about this aspect, as well as the link between the different capitals [35].

Another implication of this study is that the definition of IC provided by the Framework is not appropriate and firms do not follow it in many cases. Therefore, this definition should be revised, taking into consideration the theoretical approaches suggested by scholars and the empirical approaches emerging from the analysis of the reports prepared by firms. Indeed, the IR process seems to stimulate internal awareness regarding the relevance of the IC, although this is only a first step, to be followed by other necessary measures to mobilise its components concretely. More specifically, the investigated firms seem to be mainly concerned regarding what IC is, while the mobilisation of its components requires companies to be focused on "what IC does", to contribute to the value-creation process [59]. Accordingly, this study suggests how relevant it could be to integrate the IC debate into the IR debate.

This study has its limitations, which will be addressed by the future development of the research. Firstly, a methodological approach based on a disclosure index, which does not capture the viewpoint of managers of the investigated firms, was adopted. Therefore, future studies would benefit from a combination of this methodology with a survey or a questionnaire to be sent to managers. Additionally, the current scenario seems far from considering IR as much more than just a document where financial information (which all the investigated firms have provided) is simply combined with non-financial information. Therefore, following the different stages of IC research, further studies are required to understand how IR is utilised in practice, adopting a critical approach to assess how IC works [8]. Accordingly, future steps of the research would provide a more in-depth investigation of the content of IRs, especially in the direction of understanding the impact IRs can have on society. 
Finally, another possible development of the research would concern the extension of the field of investigation. In fact, information on IC components was searched for only in IC-specific sections of the IRs, but it cannot be excluded that this information is also disclosed in other sections of the report.

Author Contributions: All the authors jointly wrote the paper, but their primary individual contributions were as follows: Sections 1 and 3 are attributed to Michela Bianchi, Section 2 is assigned to Marco Bisogno, Section 4 is attributed to Serena Santis, and Section 5 is assigned to Alberto Incollingo.

Funding: This research was funded by "VALERE Program"—Department of Political Science, University of Campania "L. Vanvitelli".

Conflicts of Interest: The authors declare no conflict of interest.

\section{Appendix A. The List of 45 Firms}

\begin{tabular}{lclccc}
\hline 1 & Achmea & 16 & Generali & 31 & Road Accident Fund \\
2 & Aegon & 17 & Hammerson & 32 & Rsa \\
3 & Banca Fideuram & 18 & Hsbc & 33 & Sanlam Ltd. \\
4 & Bank of Ceylon & 19 & Idlc Finance & 34 & Sasria \\
5 & Bankmecu & 20 & Ing & 35 & Standard Bank Group Ltd. \\
6 & Barclays Africa Group & 21 & ItaùUnibanco Holding S.A. & 36 & Stockland \\
7 & Bndes & 22 & Lb Finance & 37 & Strate \\
8 & British Land & 23 & Liberty Holdings & 38 & Swedfund \\
9 & Capricorn Group & 24 & Lloyds Banking Group & 39 & Swedish Export Credit C. \\
10 & Ccr Sa & 25 & Mitusiand Co & 40 & Triodos \\
11 & Dbs & 26 & Msand Ad Insurance Group H. & 41 & Tskb \\
12 & Dbsa & 27 & National Australia Bank & 42 & Ubs \\
13 & Direct Line Group & 28 & Nedbank & 43 & Unicredit \\
14 & Eurazeo & 29 & Peoples Leasing and Finance & 44 & Unipol \\
15 & Fnb Namibia Holdings & 30 & Redefine International & 45 & Vancity \\
\hline
\end{tabular}

\section{Appendix B. Scoring Sheet}

\begin{tabular}{|c|c|c|c|c|c|}
\hline & sclosure Items & 2014 & 2015 & 2016 & Tot. \\
\hline \multicolumn{6}{|c|}{ Intellectual Property Category } \\
\hline 1 & Patents & \multirow{5}{*}{4} & \multirow{5}{*}{5} & \multirow{5}{*}{8} & \multirow{5}{*}{17} \\
\hline 2 & Copyrights & & & & \\
\hline 3 & Software & & & & \\
\hline 4 & Rights & & & & \\
\hline 5 & Licenses & & & & \\
\hline \multicolumn{6}{|c|}{ Organizational Capital Category } \\
\hline 6 & Knowledge & \multirow{8}{*}{6} & \multirow{8}{*}{11} & \multirow{8}{*}{18} & \multirow{8}{*}{35} \\
\hline 7 & Systems & & & & \\
\hline 8 & Procedures & & & & \\
\hline 9 & Protocols & & & & \\
\hline 10 & Databases & & & & \\
\hline 11 & Organizational routines & & & & \\
\hline 12 & Mechanism & & & & \\
\hline 13 & Structures & & & & \\
\hline \multicolumn{6}{|c|}{ Residual Category (Other) } \\
\hline 14 & Other IC components & 11 & 20 & 25 & 56 \\
\hline
\end{tabular}

\section{References}

1. Gray, R. Social, environmental and sustainability reporting and organisational value creation? Whose value? Whose creation? Account. Audit. Account. J. 2006, 19, 793-819. [CrossRef] 
2. Arvidsson, S. Disclosure of non-financial information in the annual report: A management-team perspective. J. Intellect. Cap. 2011, 12, 277-300. [CrossRef]

3. Eccles, R.G.; Serafeim, G.; Krzus, M.P. Market interest in nonfinancial information. J. Appl. Corp. Financ. 2011, 23, 113-127. [CrossRef]

4. De Villiers, C.; Rinaldi, L.; Unerman, J. Integrated Reporting: Insights, gaps and an agenda for future research. Account. Audit. Account. J. 2014, 27, 1042-1067. [CrossRef]

5. Manes-Rossi, F. Is integrated reporting a new challenge for public sector entities? Afr. J. Bus. Manag. 2018, 12, 172-187. [CrossRef]

6. IIRC International Integrated Reporting Framework. 2013. Available online: www.integratedreporting.org/ resource/international-ir-framework/ (accessed on 30 November 2018).

7. Wild, S.; van Staden, C. Integrated reporting: Initial analysis of early reporters-an institutional theory a roach. In Proceedings of the 7th Asia Pacific Interdisciplinary Research in Accounting Conference, Kobe, Japan, 26-28 July 2013; pp. 1-38.

8. Dumay, J.; Dai, T. Integrated thinking as a cultural control? Medit. Account. Res. 2017, 25, 574-604. [CrossRef]

9. Adams, S.; Simnett, R. Integrated Reporting: An Opportunity for Australia's Not for Profit Sector. Aust. Account. Rev. 2011, 21, 292-301. [CrossRef]

10. Forte, W.; Tucker, J.; Matonti, G.; Nicolo, G. Measuring the intellectual capital of Italian listed companies. J. Intellect. Cap. 2017, 18, 710-732. [CrossRef]

11. Chiucchi, M.S. Measuring and reporting intellectual capital: Lessons learnt from some interventionist research projects. J. Intellect. Cap. 2013, 14, 395-413. [CrossRef]

12. Abhayawansa, S.; Guthrie, J. Intellectual capital and the capital market: A review and synthesis. J. Hum. Resour. Costing Account. 2010, 14, 196-226. [CrossRef]

13. Melloni, G. Intellectual capital disclosure in integrated reporting: An impression management analysis. J. Intellect. Cap. 2015, 16, 661-680. [CrossRef]

14. IIRC Towards Integrated Reporting. 2011, Communicating value in the 21th Century, Discussion Paper. Available online: www.integratedreporting.org/resource/discussion-paper/ (accessed on 30 November 2018).

15. De Villiers, C.; Sharma, U. A critical reflection on the future of financial, intellectual capital, sustainability and integrated reporting. Crit. Perspect. Account. 2017. [CrossRef]

16. Guthrie, J.; Ricceri, F.; Dumay, J. Reflections and projections: A decade of intellectual capital Accounting research. Br. Account. Rev. 2012, 44, 68-82. [CrossRef]

17. Cheng, M.; Green, W.; Conradie, P.; Konishi, N.; Romi, A. The International Integrated Reporting Framework. J. Int. Financ. Manag. Account. 2014, 25. [CrossRef]

18. Eccles, R.G.; Krzus, M.P. One Report_Integrated Reporting for a Sustainable Strategy Hoboken; Wiley and Sons: Hoboken, NJ, USA, 2010.

19. Eccles, R.G.; Beiting, C.; Saltzam, D. The Landscape of Integrated Reporting. Reflections and Next Steps; Harvard Business School: Boston, MA, USA, 2010.

20. Eccles, R.G.; Krzus, M.P.; Watson, L.A. Integrated Reporting Requires Integrated Assurance in Effective Auditing for Corporates: Key Developments in Practice and Procedures; Oringel, J., Ed.; Bloomsbury Information: London, UK, 2012.

21. Eccles, R.G.; Saltzman, D. Achieving sustainability through integrated reporting. Stanf. Soc. Innov. Rev. 2011, 9, 56-61.

22. Jensen, J.C.; Berg, N. Determinants of Traditional Sustainability Reporting Versus Integrated reporting: An Institutionalist Approach. Bus. Strategy Environ. 2012, 21, 299-316. [CrossRef]

23. Owen, G. Integrated Reporting: A review of Developments and their Implications for the Accounting Curriculum. Account. Educ. Int. J. 2013, 22, 340-356. [CrossRef]

24. Abeysekera, I. A template for integrated reporting. J. Intellect. Cap. 2013, 14, 227-245. [CrossRef]

25. Incollingo, A. Le Prime Esperienze di Bilancio Integrato. Analisi e Riflessioni; Giappichelli: Turin, Italy, 2014.

26. Adams, C.A.; Potter, B.; Singh, P.J.; York, J. Exploring the implications of integrated reporting for social investment disclosures. Br. Account. Rev. 2016, 48, 283-296. [CrossRef]

27. Eccles, R.G.; Krzus, M.P.; Ribot, S. Models of best practice in integrated reporting. J. Appl. Corp. Finance 2015, 27, 103-115. [CrossRef]

28. Ahmed Haji, A.; Anifowose, M. Initial trends in corporate disclosures following the introduction of integrated reporting practice in South Africa. J. Intellect. Cap. 2017, 18, 373-399. [CrossRef] 
29. Feng, T.; Cummings, L.; Tweedie, D. Exploring integrated thinking in integrated reporting-An exploratory study in Australia. J. Intellect. Cap. 2017, 18, 330-353. [CrossRef]

30. Gibassier, D.; Rodrigue, M.; Arjaliès, D.L. Integrated Reporting Is Like God: No One Has Met Him, but Everybody Talks About Him. The Power of Myths in the Adoption of Management Innovations. Account. Audit. Account. J. 2018. [CrossRef]

31. Beck, C.; Dumay, J.; Frost, G. In pursuit of a 'single source of truth': From threatened legitimacy to integrated reporting. J. Bus. Ethics 2017, 141, 191-205. [CrossRef]

32. Chen, Y.P.; Perrin, S. Insights into Integrated Reporting: Challenges and Best Practice Responses, Association of Chartered Certified Accountants ACCA; ACCA: London, UK, 2017.

33. Camodeca, R.; Almici, A. Implementing Integrated Reporting: Case Studies from the Italian Listed Companies. Account. Finance Res. 2017, 6. [CrossRef]

34. Ruiz-Lozano, M.; Tirado-Valencia, P. Do industrial companies respond to the guiding principles of the Integrated Reporting framework? A preliminary study on the first companies joined to the initiative. Rev. Contab. 2016. [CrossRef]

35. Incollingo, A.; Bianchi, M. The Connectivity of Information in Integrated Reporting. Empirical Evidence from International Context. Financ. Rep. 2016, 2, 55-79. [CrossRef]

36. Mio, C.; Fasan, M.; Pauluzzo, R. Internal application of IR principles: Generali's Internal Integrated Reporting. J. Clean. Prod. 2016, 139, 204-218. [CrossRef]

37. Melloni, G.; Caglio, A.; Perego, P. Saying More with Less? Disclosure Conciseness, Completeness and Balance in Integrated Reports. J. Account. Public Polic. 2017, 36, 220-238. [CrossRef]

38. Zhou, S.; Simnett, R.; Green, W. Does Integrated Reporting Matter to the Capital Market? Abacus 2017, 53, 94-132. [CrossRef]

39. Higgins, C.; Stubbs, W.; Love, T. Walking the talk(s): Organisational narratives of integrated reporting. Account. Audit. Account. J. 2014, 27, 1090-1119. [CrossRef]

40. Brown, J.; Dillard, J. Integrated reporting: On the need for broadening out and opening up. Account. Audit. Account. J. 2014, 27, 1120-1156. [CrossRef]

41. Flower, J. The international integrated reporting council: A story of failure. Crit. Perspect. Account. 2015, 27, 1-17. [CrossRef]

42. Dumay, J.; Bernardi, C.; Guthrie, J.; Demartini, P. Integrated Reporting: A structured literature review. Account. Forum 2016, 40, 166-185. [CrossRef]

43. De Villiers, C.; Venter, E.R.; Hsiao, P.K. Integrated Reporting: Background, Measurement Issues, A roaches and an Agenda for Future Research. Account. Financ. 2017, 57, 937-959. [CrossRef]

44. Perego, P.; Kennedy, S.; Whiteman, G. A lot of icing but little cake? Taking integrated reporting forward. J. Clean. Prod. 2016, 136, 53-64. [CrossRef]

45. Romolini, A.; Fissi, S.; Gori, E. Exploring Integrated Reporting Research: Results and Perspectives. Int. J. Account. Financ. Rep. 2017, 7, 32-59. [CrossRef]

46. Velte, P.; Stawinoga, M. Integrated Reporting: The Current State of Empirical Research, Limitations and Future Research Implications. J. Manag. Control. 2017, 28, 275-320. [CrossRef]

47. Dumay, J. A critical reflection on the future of intellectual capital: From reporting to disclosure. J. Intellect. Cap. 2016, 17, 168-184. [CrossRef]

48. Sveiby, K.E. Intangible assets monitor. J. Hum. Resour. Costing Account. 1997, 2, 73-79. [CrossRef]

49. Dumay, J. 15 years of the Journal of Intellectual Capital and counting: A manifesto for transformational IC research. J. Intellect. Cap. 2014, 15, 2-37. [CrossRef]

50. Wang, Q.; Sharma, U.; Davey, H. Intellectual capital disclosure in Chinese and Indian information technology companies: A comparative analysis. J. Intellect. Cap. 2016, 17, 507-529. [CrossRef]

51. Roos, G.; Roos, J. Measuring your company's intellectual performance. Long Range Plan. 1997, 30, 413-426. [CrossRef]

52. Stewart, T.A. Intellectual Capital: The New Wealth of Organisations; Doubleday/Currency: New York, NY, USA, 1997.

53. Bontis, N. Intellectual capital: An exploratory study that develops measures and models. Manag. Decis. 1998, 36, 63-76. [CrossRef]

54. Guthrie, J.; Petty, R. Intellectual capital: Australian annual reporting practices. J. Intellect. Cap. 2000, 13, 241-251. [CrossRef] 
55. Duff, A. Intellectual capital disclosure: Evidence from UK accounting firms. J. Intellect. Cap. 2018, 19, 768-786. [CrossRef]

56. Curado, C.; Henriques, L.; Bontis, N. Intellectual capital disclosure payback. Manag. Decis. 2011, 49, 1080-1098. [CrossRef]

57. Mouritsen, J.; Roslender, R. Critical intellectual capital. Crit. Perspect. Account. 2009, 20, 801-803. [CrossRef]

58. Zambon, S. Ten years after: The past, the present and the future of scholarly investigation on intangibles and intellectual capital. J. Intellect. Cap. 2016, 17. [CrossRef]

59. Badia, F.; Dicuonzo, G.; Petruzzelli, S.; Dell'Atti, V. Integrated reporting in action: Mobilizing intellectual capital to improve management and governance practices. J. Manag. Gov. 2018, 1-22. [CrossRef]

60. Abeysekera, I.; Guthrie, J. Human capital reporting in a developing nation. Br. Account. Rev. 2004, 36, 251-268. [CrossRef]

61. Dumay, J.; Bernardi, C.; Guthrie, J.; La Torre, M. Barriers to implementing the International Integrated Reporting Framework: A contemporary academic perspective. Medit. Account. Res. 2017, 25, 461-480. [CrossRef]

62. Mouritsen, J. Problematising intellectual capital research: Ostensive versus performative IC. Account. Audit. Account. J. 2006, 19, 820-841. [CrossRef]

63. Beattie, V.A.; McInnes, B.; Fearnley, S. A methodology for analyzing and evaluating narratives in annual reports: A comprehensive descriptive profile and metrics for disclosure quality attributes. Account. Forum 2004, 28, 205-236. [CrossRef]

64. Marston, C.L.; Shrives, P.J. The use of disclosure indices in accounting research: A review article. Br. Account. Rev. 1991, 23, 195-210. [CrossRef]

65. Holsti, O.R. Content Analysis for the Social Sciences and Humanities; Addison-Wesley: Boston, MA, USA, 1969.

66. Krippendorff, K. Content Analysis. an Introduction to Its Methodology; SAGE, Inc.: Thousand Oaks, CA, USA, 2013.

67. Weber, R.P. Basic Content Analysis, 2nd ed.; Sage: London, UK, 1990.

68. Dumay, J.; Garanina, T. Intellectual capital research: A critical examination of the third stage. J. Intellect. Cap. 2013, 14, 10-25. [CrossRef]

69. Cooke, T.E. Voluntary Corporate Disclosure by Swedish Companies. J. Int. Financ. Manag. Account. 1989, 1, 171-195. [CrossRef]

70. Hassan, O.; Marston, C.L. Disclosure Measurement in the empirical Accounting literature-A review article. Recuper. Em. 2010. [CrossRef] 